Check for updates

1 National Voices, London, UK

2 Richmond Group of Charities, London, UK

3 Healthwatch England, London, UK

Correspondence to: C Augst charlotte.augst@nationalvoices.org.uk Cite this as: BMJ 2021;374:n1979 http://dx.doi.org/10.1136/bmj.n1979

Published: 13 August 2021

\section{England's health and care bill neglects service users' voice}

\author{
Users should be equal partners with NHS and local government \\ Charlotte Augst, ${ }^{1}$ Neil Tester, ${ }^{2}$ Imelda Redmond ${ }^{3}$
}

The health service in England is undergoing its first major legislative reform in almost a decade. At its heart, the new health and care bill is all about integration ${ }^{1}$ : doing away with the internal market, ending competition, and promoting collaboration to get the best health outcomes for patients and the public and generate best value for taxpayers.

Importantly for a piece of health legislation, the bill also sets out an equal role for local government. This means that strategies for health, social care, and public health can be considered collectively, an idea that has had broad support for some time. ${ }^{2}$

There is also widespread backing for the principle of subsidiarity that runs throughout the bill, with organisations closest to the problems being given the power to solve them.

For those working in healthcare, this combination opens up various opportunities to do things differently, if all stakeholders choose to seize them. Health leaders will need to think hard about how they build on existing mechanisms for joint working rather than reinventing the wheel-for example, how to use the current joint strategic needs assessments, which evaluate local health and care needs, to support planning at all levels of decision making.

What does the bill mean for health and care users? Firstly, communities' needs will be considered holistically rather than being constrained by separate and rigid pathways of care. Secondly, future services should be designed from the bottom up, with communities playing a key role. With the right investment, existing community infrastructure, including local Healthwatch services ${ }^{3}$ and the voluntary sector, can ensure that decisions made in the government's proposed "places" focus relentlessly on the needs of citizens.

However, the bill misses an opportunity with integrated care systems (ICSs), the new higher level strategic tier of decision making. Making the governance of ICSs a partnership between the NHS and local government is vital, but the relationship remains unbalanced in favour of those providing services. ICSs must also be completely in tune with the communities they serve or risk wasting scarce time and resources on ill considered plans.

\section{Tripod}

ICS boards, the bodies responsible for the most critical financial decisions in these new structures, should develop and implement a strong and independent mechanism enabling service users to contribute equally alongside NHS and local government partners. This would ensure users' experiences and insights are pulled together, giving the leadership critical information about what communities want and need to stay well. This tripod power structure could also help track the success or failure of interventions and facilitate more timely and appropriate public scrutiny of decisions.

The government is right to rule out legislating in detail on how the role of service users should work. The voluntary sector, for example, varies considerably from one area to the next, so a single approach would not be appropriate. But the new legislation is an opportunity to strengthen the voice of users in decision making and ensure that every area of the country gives this leg of the tripod the status it deserves. Healthwatch England, as the existing statutory champion, could have a clearer role in supporting ICSs to achieve this goal.

NHS England's draft guidance ${ }^{4}$ on setting up ICSs is more detailed and progressive than the legislation itself. The guidance emphasises that every ICS is expected to develop and implement a range of user engagement approaches at every level of decision making, and to prioritise engagement with groups experiencing health inequalities, including people from ethnic minorities or with disabilities. The guidance also states that these arrangements should be a source of genuine co-production not just user commentary, and a key tool for supporting accountability and transparency.

As with all guidance, however, compliance is not guaranteed. Measures to strengthen the user voice should be included in the legislation to give the guidance backing.

User organisations and community champions need more than just a seat at the table. Representation on the boards of ICSs is important but not enough. The narrative around the new health and care bill must give the views and experiences of healthcare users-including those with limited access to services-equal status with clinical and financial considerations. For example, the experiences of care should receive the same weight as costs or narrowly defined clinical outcomes in procurement decisions.

Some ICSs are already working closely with and through their communities. ${ }^{56}$ But the health and care bill should be amended to make this the norm across all 42 ICSs in England.

Competing interests: We have read and understood BMJ policy on declaration of interests and declare that CA and NT sit on an advisory board for the Association of the British Pharmaceutical Industry.

Provenance and peer review: Commissioned; not externally peer reviewed.

Alderwick H, Gardner T, Mays N. England's new health and care bill. BMJ 2021:374-n1767. doi: 10.1136/bmj.n1767. pmid: 34257143 
2 NHS England, NHS Improvement. The NHS's recommendations to government and parliament for an NHS Bill. 2019. https://www.england.nhs.uk/wp-content/uploads/2019/09/BM1917-NHSrecommendations-Government-Parliament-for-an-NHS-Bill.pd

3 Healthwatch. Our history and functions. https://www.healthwatch.co.uk/our-history-and-functions

4 NHS England. Integrated care systems: design framework. 2021. https://www.england.nhs.uk/wpcontent/uploads/2021/06/B0642-ics-design-framework-june-2021.pdf

5 West Yorkshire and Harrogate Health and Care Partnership. About us. https://www.wyhpartnership.co.uk/about

6 Healthwatch South East London has a new director. 2020 https://healthwatchgreenwich.co.uk/news/2020-04-21/healthwatch-south-east-london-has-new-director 